\title{
A crescente disseminação dos estudos feministas na pesquisa em Artes Cênicas e suas contribuições para a criação de ações disruptivas institucionais
}

The spreading of feminist approaches as research in the Performing Arts and their contribution towards the creation of disruptive institutional actions

Stela Fischer ${ }^{1}$ 


\section{Resumo}

Proponho uma mirada em direção à crescente disseminação dos estudos feministas e de gênero nos programas de graduação e pós-graduação em Artes Cênicas em diversas instituições brasileiras. O texto aborda o incentivo à inclusão de disciplinas curriculares, criação de encontros e núcleos de pesquisas teóricas e artísticas, e de frentes pedagógicas associadas aos estudos feministas, identitários e decoloniais na formação da/o artista. Essa condição impulsiona abordagens de outras epistemologias e estabelecem uma reação crítica diante da - ainda - predominância dos saberes hegemônicos e/ou androcêntricos institucionais.

Palavras-chave: Teatro feminista; mulheres artistas; epistemologia feminista; epistemologia decolonial; feminismos

\section{Abstract}

In this paper, I propose to take a look on the growing diffusion of feminist and gender studies in undergraduate and graduate programs within theatre departments in Brazilian institutions of higher education. The paper addresses the stimulus to include the subject matter through curricular courses, meetings and the creation of theoretical and practical research groups as well as closely linked pedagogic activities that are associated with feminist, identity and decolonial studies within the artist's formative process. This conditioning context serves as a stimules to get in touch with other non-hegemonic epistemologies e establishes a critical reaction towards what are still predominant forms of institutional knowledge, such as androcentric approaches.

Keywords: Feminist theatre; female artists; feminist epistemology; decolonial epistemology; feminism(s) 


\section{Constelações}

Este texto propõe uma reflexão sobre o crescente interesse e disseminação dos estudos feministas e de gênero na produção acadêmica nos programas de graduação e pós-graduação em Artes Cênicas em diversas instituições brasileiras, realizadas por mulheres pesquisadoras, com recorte para as temáticas feministas. São trabalhos acadêmicos e artísticos, dissertações, teses, criação de núcleos de pesquisa e encontros que somam ao fluxo de rupturas do silenciamento histórico das mulheres na universidade, assim como estabelecem uma postura crítica em relação ao androcentrismo epistêmico e institucional. ${ }^{2}$

Esta condição dá-se por uma conjuntura de fatores históricos e da ordem do dia. Um deles é instaurado, com a devida relevância, pela atuação de docentes com formação multidisciplinar em artes, associada aos estudos feministas e de gênero. Docentes que têm desenvolvido ações pedagógicas disruptivas ao empreenderem a inclusão de disciplinas curriculares, orientação de trabalhos e grupos de pesquisas, e de frentes associadas aos movimentos sociais identitários e de gênero nos cursos superiores de formação da/o artista. Na maioria, são ações isoladas, de iniciativas das/os próprias/os docentes e apresentam-se como ressalvas nas dinâmicas institucionais brasileiras. Ao apurar outras perspectivas teóricas e práticas que criam fissuras na escritura das histórias das mulheres nos estudos feministas nas artes da cena, há um incentivo na articulação de epistemologias que estabelecem uma reação crítica em direção à - ainda! - predominância do discurso acadêmico hegemônico e androcêntrico. Estas coalizões atuam nos níveis teórico-epistemológicos e artísticos, driblando a ausência das abordagens críticas feministas e decoloniais enquanto saberes legítimos e integrados aos currículos universitários em Artes Cênicas, e promovem uma transgressão de caráter ativista intrínseca à ética do próprio movimento feminista na construção de lugares outros, de saber e poder. Afinal, os desafios dos feminismos e suas lutas são contínuos e devemos desarticular toda frente de opressão e omissão em qualquer ambiente, bem como "formular novas constelações para pensar a normatividade, se quisermos proceder de maneiras intelectualmente abertas e compreensivas a fim de compreender e avaliar o mundo em que vivemos" (Butler, 2015, p. 207).

E ao abrir esta reflexão identificando a importância do papel de docentes diante da criação de iniciativas desbravadoras em pesquisas científicas feministas nas Artes Cênicas, destaco a fala aguerrida da atriz e professora Luciana Lyra, no ensejo da edição do Dossiê da Revista Arte da $\mathrm{Cena}^{3}$, dedicado às pesquisas e produções artísticas feministas, de âmbito nacional:

Alijadas, por séculos, de atividades ligadas ao intelecto e ao bem público, duvidadas no que tange à sua capacidade racional e de pensamento, mulheres sofrem com o silenciamento compulsório e a submissão ao discurso patriarcal

\footnotetext{
${ }^{2}$ No Brasil, essa reflexão vem sendo proposta insistentemente por professoras como Margareth Rago (UNICAMP), Rita Laura Segato (UnB), Miriam Pillar Grossi (UFSC) e Guacira Lopes Louro (UFRGS), na área de Ciências Humanas e Educação e Margarida (Margie) Rauen (UNICENTRO), em Artes Cênicas e Letras, para citar apenas algumas iniciativas históricas.
}

${ }^{3}$ Disponível em: <https://www.revistas.ufg.br/artce/issue/view/1859>. Acesso em: set. 2018. 
em âmbito mundial. Tal obscurecimento e invisibilidade alcança massivamente os diversos nichos de conhecimento e atinge invariavelmente os espaços acadêmicos. Contudo, nos últimos vinte anos, vem se desvelando a notória e decisiva contribuição de várias pesquisadoras, entre professoras e alunas, em contexto internacional, e em específico no caso brasileiro.

No campo das Artes da Cena, a quantidade e qualidade das investigações traçadas por mulheres no Brasil é evidente. O impacto de monografias, dissertações, teses, produções bibliográficas diversas, palestras e apresentações públicas desenvolvidas por mulheres está em franco crescimento, tramando uma rede de discussões que acaba por ligar várias pesquisadoras na luta contra a perspectiva falocêntrica impetrada na academia. (Lyra, 2017, p. 3)

Lyra é uma das professoras que vem empreendendo estratégias à contramão do patriarcalismo acadêmico, com orientação de trabalhos acadêmicos e a criação do grupo de pesquisa MOTIM - mito, ritos e cartografias femininas nas artes, em 2015, sediado na Universidade do Estado do Rio de Janeiro (UERJ).

Anterior a esta colaboração, tantas outras colegas que - ao final formam redes de resistência e luta das mulheres artistas pesquisadoras - inauguraram os estudos feministas nas instituições brasileiras de ensino em Artes Cênicas, e merecem ser aqui reverenciadas. ${ }^{4}$ Presenças como a de Marisa Naspolini, em sua atuação como artista feminista e professora colaboradora do Departamento de Artes Cênicas da Universidade Estadual de Santa Catarina (UDESC), entre os anos de 1993-1994 e 2001-2010. É a idealizadora e coordena o Vértice Brasil, primeiro e importante festival internacional de teatro feito por mulheres no Brasil, vinculado ao The Magdalena Project, rede internacional de mulheres artistas do teatro. ${ }^{5}$ Junto à Naspolini, participam da organização e condução do Vértice Brasil Barbara Biscaro, Glaucia Grigolo e Monica Siedler. O evento teve a sua primeira edição em 2008, sob o título Encontro e Festival de Teatro Feito por Mulheres; seguido de Travessia, em 2010; T(i)erra Firme, em 2012; e Em Residência, em 2014. Os encontros do Vértice Brasil oferecem uma programação intensa, envolvendo apresentação de espetáculos, oficinas e atividades formativas, espaços abertos para demonstrações de trabalhos, assim como a convivência em grupo que favorecem a

formação de redes auto-organizativas, que transformam a ideia do 'empoderamento feminino' [...] em termos condizentes com a realidade do novo século, quando as ideias de diversidade pedem a invenção de novas formulações para a coletividade e outros modelos de relações em colaboração. (Romano, 2009, p. 422)

A iniciativa de Naspolini de criar uma vertente nacional do The Magdalena Project chamou a atenção para a lacuna na prática e nos estudos da cena contemporânea nacional quando se trata da discussão sobre a presença das mulheres atrizes, performers, pesquisadoras e artistas da cena como impulsoras de discursos críticos,

\footnotetext{
${ }^{4}$ Vale lembrar que antes das iniciativas aqui elencadas, as primevas publicações Um teatro da mulher - dramaturgia feminina no palco brasileiro contemporâneo (Perspectiva, 1992), de Elza Cunha Vincenzo, assim como A mulher e o Teatro Brasileiro do século XX (Hucitec, 2008), das professoras Ana Lúcia de Andrade e Ana Maria de B. Edelweiss (ambas da UFRJ), e A tradição obscura: o teatro feminino no Brasil (Bacantes, 2001), de Maria Cristina de Souza, são obras originárias de estudos sobre as mulheres na cena brasileira.

${ }^{5}$ The Magdalena Project (1986) é uma rede internacional de mulheres artistas do teatro cuja meta principal é o intercâmbio e incentivo à reflexão crítica sobre a mulher no teatro contemporâneo. Promove encontros periódicos que objetivam agregar mulheres artistas em atividades de compartilhamento de experiências, como workshops, debates, demonstrações de trabalhos e apresentações artísticas. Mais informações no site <www.themagdalenaproject.org>. Acesso em: set. 2018.
} 
de criação de metodologias, de pesquisas e ações no campo das Artes Cênicas. E colaborou para o surgimento de espaços de encontro, intercâmbio e criação de redes entre mulheres artistas, algo inédito no Brasil. Atualmente, Naspolini está vinculada ao Programa de Mestrado Profissional em Artes na UDESC, com condução de grupos de pesquisa e orientação de dissertações de mestrado em estudos feministas e de gênero. Também atua ativamente na área de políticas culturais, gestão da cultura e questões de gênero da cidade de Florianópolis.

O mesmo destaque para a Profa. Dra. Maria Brígida de Miranda que, assim como Naspolini, introduziu os estudos de gênero e feminismos no Departamento de Artes Cênicas da UDESC, a partir do seu ingresso em 2004, como professora no curso de Licenciatura em Teatro. Desde então, desenvolve reflexões sobre as questões de gênero e teatro feminista em sala de aula, orientações de trabalhos de conclusão de curso, dissertações e teses na área de gênero e teatro feminista e criou o grupo de pesquisa em gênero "Poéticas do Feminino e Masculino". Em 2007, realizou a montagem do espetáculo teatral feminista no curso de Teatro da UDESC, Vinegar Tom (1976), da inglesa Caryl Churchill que foi apresentado dentro da universidade, como em outros teatros e festivais na cidade de Florianópolis. Em 2008, a convite de Marisa Naspolini, De Miranda proferiu a palestra "Mulheres Invisíveis e Espaços Ginocêntricos", na primeira edição do Vértice Brasilt ${ }^{6}$, em Florianópolis. A fala abordou a invisibilidade do trabalho das mulheres na história do teatro e apontou algumas das estratégias do teatro feminista em países anglofonos e causou impacto:

Porque naquele momento poucas mulheres de teatro se assumiam interessadas em se dizerem feministas. E a ideia sobre teatro feminista era bem distante do que a maioria entendia como "teatro de mulheres" ou "teatro feminino". Mas acredito que a fala gerou alguns ecos. (Miranda, 2018)

Em 2009, De Miranda organizou junto com a Profa. Dra. Lúcia Romano o primeiro Simpósio Temático Teatro e Gênero a integrar o reconhecido evento Seminário Internacional Fazendo Gênero, realizado na Universidade Federal de Santa Catarina (UFSC). Também em 2009, traduziu e encenou o texto teatral Retrato de Augustine (1990), das dramaturgas australianas feministas Peta Tait e Matra Robertson. A montagem foi contemplada como Prêmio Myriam Muniz (2008), sendo apresentada entre 2010 e 2012 em diferentes espaços de Florianópolis e outras cidades, como Chapecó e Lages (SC). Em 2017, criou e ministrou a disciplina "Introdução ao Teatro Feminista" no Programa de Pós-graduação em Teatro - PPGT/UDESC.7 Essas trajetórias contínuas de De Miranda e Naspolini demonstram percursos que associam ativismo, ações artísticas e pedagógicas feministas que inauguram uma fase de acessibilidade e disseminação dos estudos de gênero na pesquisa acadêmica em Artes Cênicas no Brasil de hoje.

Outro nome a ser celebrado é o da Profa. Dra. Lúcia Romano, que teve sua tese

\footnotetext{
${ }^{6}$ Esta primeira edição do Vértice Brasil aconteceu de 14 a 19 de julho de 2008, em Florianópolis. A programação compreendeu em ofertas de oficinas, tais como: "A Presença da Performer Feminina", com Jill Greenhalgh; "O Eco do Silêncio", com Julia Varley; "Diretora-Norteadora", com Leo Sykes (Udigrudi); "Confissão e Ação", com Marisa Naspolini; e "Corpo Multifacetado", com Ana Cristina Colla (LUME Teatro). Também contou com roda de conversas e apresentação de espetáculos e demonstrações de trabalhos cênicos de várias artistas regionais, nacionais e internacionais.
}

${ }^{7}$ Estas informações foram coligidas na entrevista com a Profa. Brígida de Miranda, concedida a Stela Fischer, por e-mail, em 28 de set. 2018. 
de doutoramento defendida em $2009^{8}$ e abriu uma seara de novas pesquisas em teatro feminista. Como docente da Universidade Estadual Paulista (UNESP), orienta diversos trabalhos e oferta disciplinas com recortes feministas no Programa de Pós-Graduação em Artes na UNESP. ${ }^{9}$ O mesmo para a Profa. Dra. Nina Caetano, da Universidade Federal de Ouro Preto (UFOP), na qual é docente e orientadora no curso de pós-graduação do DEART/UFOP e coordena os grupos de pesquisas Híbrida - poéticas híbridas da cena contemporânea (CNPq), Ninfeias - Núcleo de investigações feministas e Obscena que empreendem investigações em torno das escritas performadas, intervenções urbanas, feminismos e estudos de gênero. Seus nomes e pesquisas têm sido referências para diversas pesquisadoras da cena feminista brasileira.

Outras presenças que requerem notabilidade são a da Profa. Dra. Veronica Fabrini, na Universidade Estadual de Campinas (UNICAMP); Profa. Dra. Ana Bernstein, na Universidade Federal do Estado do Rio de Janeiro (UNIRIO); Profa. Dra. Mara Leal, da Universidade Federal de Uberlândia (UFU); Profa. Dra. Margarida (Margie) Rauen, na Universidade Estadual do Centro Oeste, Paraná (UNICENTRO); Profa. Dra. Guaraci Martins e - autorreferindo-me - Profa. Dra. Stela Fischer, na Universidade Estadual do Paraná (UNESPAR); Prof. Dr. Ferdinando Martins, na Universidade de São Paulo (USP), para citar apenas alguns nomes que permanecem como referências no atual estabelecimento de currículos menos androcêntricos em cursos de Artes Cênicas ou ao propor práticas pedagógicas que levam à reflexão acerca dos estudos de gênero e sexualidade, assuntos necessariamente colados a qualquer época da vida e âmbito profissional.

\section{A Universidade que desejamos}

Essa realidade que se apresenta nestes últimos anos, faz-me lembrar de que na minha formação, desde as séries iniciais até a universidade, os estudos feministas não foram abordados, pois o debate político sobre gênero no sistema educacional brasileiro é, por vezes, escasso, controverso ou blindado. ${ }^{10} \mathrm{~A}$ genealogia dos meus estudos feministas aconteceu na relação direta com movimentos sociais e nas frestas dos ensinos em artes talhadas por uma dinâmica muitas vezes autodidata - embora sempre em diálogo com professoras e colegas - nos quais pude experimentar a interlocução entre pesquisa acadêmica, arte, cidadania e modos de existir, considerando as reivindicações e saberes feministas.

A desestabilização das práticas culturais institucionais androcêntricas e a criação de espaços à margem do status quo ainda requerem transformações substanciais para incentivar a construção de subjetividades e autorrepresentações pertinentes aos feminismos e aos estudos de gênero. As mesmas resultam de ações e políticas das

\footnotetext{
${ }^{8}$ Lúcia R. V. Romano. De quem é esse corpo? A performatividade do feminino no teatro contemporâneo. Tese (Doutorado). São Paulo: Departamento de Artes Cênicas, Escola de Comunicação e Artes, Universidade de São Paulo, 2009.

${ }^{9}$ Sob orientação da Profa. Dra. Lúcia Romano, participei como aluna regular da disciplina "A performatividade do gênero feminino no teatro: invenção cênica e pedagogia", ofertada em 2014, no Programa de Pós-graduação em Artes, da Universidade Estadual Paulista (UNESP).

${ }^{10}$ Repudio a forma deliberadamente distorcida que gênero vem sendo tratado nas políticas públicas associadas a grupos religiosos, blindando o debate no sistema educacional do Brasil de hoje. Como é o caso do Projeto de Lei 2731, de 2015, idealizado pelo deputado federal Eros Biondini (PTB-MG). Ele propõe alterar o Plano Nacional de Educação (PNE) para proibir o debate sobre gênero na educação nacional. O documento prevê pena de prisão para os professores que desrespeitarem a determinação. Disponível em: <https://educacaointegral.org.br/reportagens/projeto-de-lei-preve-prisao-de-docente-que-falar-sobre-ideologia-de-genero>. Acesso: set. 2018.
} 
mulheres apoiadas em inversões dos discursos de saber e poder (Lauretis, 2000, p. 8). Nesses processos, é inegável a importância da universidade na produção e difusão da teoria crítica dos feminismos e dos estudos de gênero, nos diversos campos do conhecimento, que legitimaram os direitos civis e incentivam os processos intelectuais, as modificações comportamentais e os marcadores sociais. De acordo com a historiadora feminista Margareth Rago, "não há dúvidas de que o modo feminista de pensar rompe com os modelos hierárquicos de funcionamento da ciência e com vários dos pressupostos da pesquisa científica" (Rago, 1998, p. 10). Este tem sido um procedimento usual em instituições de ensino superior de países norte-americanos e europeus, acompanhando o desenvolvimento interdisciplinar dos estudos de mulheres e estudos de gênero (women's studies e gender studies), desde os anos 1970, inclusive no campo da performance e do teatro.

Por exemplo, na New York University, além do programa Gender and Sexuality Studies, vinculado ao departamento Social and Cultural Analysis, existem grupos de estudos dentro do próprio departamento de Performance Studies dedicados à sexualidade e gênero. Desenvolvem encaminhamentos de formação do artista, processos criativos e publicações como Women \& Performance: A Journal of Femnist Theory $(1983)^{11}$ produzida por um coletivo feminista composto de estudantes, artistas e professores/as do departamento de Performance Studies. Outra via de disseminação são projetos como o Instituto Hemisférico de Performance e Política ${ }^{12}$ que também agrega artistas pesquisadores de diversas nacionalidades, interessados nas discussões e expressões de gênero. Um segundo exemplo é a Stockholm Academy of Dramatic Arts, da Universidade de Estocolmo, que desenvolve um projeto próprio intitulado Staging Gender ${ }^{13}$, com ênfase nos estudos de gênero na perspectiva do treinamento do ator e seu desenvolvimento artístico e pedagógico. Os objetivos abrangem quatro áreas de aplicação: performance, teatro, poesia e teatro musical. O projeto é realizado em colaboração de diferentes instituições, como a Academy of Music and Drama, da Universityof Gothenburg; a Malmö Academy of Theatre, da Lund University; a Theatre Academy, da Luleå University. Esses dois exemplos (apenas dois entre muitos!) demonstram que são variadas as instituições estrangeiras de ensino superior em artes interessadas em expandir programas e projetos que tratam dos estudos de gênero no momento da formação da/o artista.

No Brasil, há algumas décadas, diferentes departamentos de cursos superiores de Ciências Sociais, Humanidades e Filosofia de diferentes instituições oferecem iniciativas interdisciplinares de pesquisas voltadas à produção do conhecimento em torno da problemática de gênero. A maioria corresponde a núcleos de produção teórica, sendo alguns deles dedicados à publicação de revistas, livros e traduções de textos relevantes sobre o tema. ${ }^{14}$

\footnotetext{
${ }^{11}$ Disponível em: < https://www.tandfonline.com/loi/rwap20>. Acesso em: set.2018.

${ }^{12}$ Sobre o Instituto: http://hemisphericinstitute.org. Acesso em: set. 2018.

${ }^{13} \mathrm{O}$ catálogo do projeto Staging Gender está disponível em: https://hsm.gu.se/digitalAssets/1311/1311021_staging_gender.pdf. Acesso em: set. 2018.

${ }^{14}$ Como o Núcleo de Estudos Interdisciplinares sobre a Mulher (NEIM/UFBA), vinculado à Universidade Federal da Bahia, abriga o curso de Pós-Graduação (Mestrado e Doutorado) em Estudos Interdisciplinares sobre Mulheres, Gênero e Feminismo (PPGNEIM), o primeiro nessa temática no país e na América Latina e o curso de Bacharelado em Estudos de Gênero e Diversidade com concentração em Políticas Públicas; o Núcleo de Estudos da Mulher e Relações Sociais do Gênero, da Universidade de São Paulo; Núcleo de Estudos de Gênero Pagu, da Universidade Estadual de Campinas; Instituto de Estudos de Gênero do Centro
} 
Salvo as exceções de iniciativas docentes e pedagógicas citadas anteriormente, o mesmo não se apresenta de maneira abrangente nos departamentos de cursos superiores de Artes Cênicas:

No currículo tradicional das escolas de teatro, grande parte da produção teatral contemporânea deixa de adquirir visibilidade quando são suprimidas as discussões em torno da história do teatro e da performance feministas, da análise de processos de trabalho e criadoras mulheres, da diferença sexual no treinamento dos atores, de uma sociologia e história do comediante a partir das diferenças sexuais, da estruturação do gênero na produção teatral (o caráter masculino ou feminino da profissão teatral, por exemplo). (Romano, 2009, p. 123)

A citação de Romano valida a pertinência de uma mirada ao incentivo e valorização dos estudos de gênero no âmbito dos conhecimentos, das habilidades e da produção artística. Em defesa da inclusão de disciplinas e atividades teóricas e práticas sobre gênero e sexualidade, assim como o "engajamento de docentes como agentes questionadores e propositores de currículos (Batista; Rauen, 2017, p. 93) e de frentes que possibilitem abordar a temática na esfera das artes da cena, afinal:

Tanto docentes em formação, quanto professores já atuantes devem recorrer à pesquisa voltada ao enriquecimento e atualizações de suas práticas. Aos membros de conselhos departamentais ou colegiados, resta o desafio de instigar a inclusão de componentes curriculares representativos da diversidade de gêneros.

Outra frente que possibilita a disseminação de pesquisas de gênero nos cursos superiores de Artes Cênicas é o agenciamento de encontros e grupos de pesquisas, muitas vezes informais, sem nenhum tipo de financiamento. A criação de núcleos de pesquisa vem construindo espaços de permuta, conceituação e aprofundamento de teorias e metodologias feministas. E também congressos e seminários que promovem atividades de formação e compartilhamento sobre os estudos feministas e de gênero, como o Seminário Internacional Fazendo Gênero, em Florianópolis, que teve sua $11^{\text {a }}$ edição realizada em 2017, juntamente com o 13th Women's Worlds (WW) Congress ${ }^{15}$; o Seminário Internacional Desfazendo Gênero, em sua 3ạ. edição em Campina Grande (Paraíba), em 2017; o 3ㅇ. Simpósio Internacional Reflexões da Cena Contemporânea, com parte de sua programação dedicada ao debate "A Produção Cênica da Mulher na Contemporaneidade", organizado pelo LUME Teatro e Universidade Estadual de Campinas, em 2014. Ou ainda, encontros propostos fora do ambiente universitário, mas não menos importantes, como o Seminário "A Arte Feminista e a Crítica Cultural", oferecido pelo Centro de Pesquisa do Sesc/SP, em 2016; Seminário “Diálogos sobre o Feminino", no Centro Cultural Banco do Brasil de São Paulo, também em 2016; o ELLA - Encontro Latino-americano de Mulheres,

\footnotetext{
de Filosofia e Ciências Humanas, da Universidade Federal de Santa Catarina; Núcleo de Estudos e Pesquisas Sobre a Mulher, da Universidade de Brasília; Núcleo Interdisciplinar de Estudos sobre a Mulher, da Universidade Federal do Rio Grande do Sul; e Núcleo de Estudos de Sexualidade e Gênero, do Instituto de Filosofia e Ciências Sociais da Universidade Federal do Rio de Janeiro, entre outros exemplos, muitos citados na tese de doutoramento de Lucia Romano (Romano, 2009, p. 120).

${ }^{15} \mathrm{Na}$ área de artes da cena, o encontro ofereceu o Simpósio Temático "Engendramentos da cena: práticas teatrais feministas na contemporaneidade", coordenado pelas professoras Luciana Lyra (UERJ) e Maria Brígida de Miranda (UDESC) que teve 40 trabalhos acadêmicos apresentados em formato de comunicações e publicados nos anais do evento.
} 
realizado em Belo Horizonte, em 2014;16 o Festival Autônomo Feminista, em São Paulo, organizado de forma independente pelo Coletivo 2a ${ }^{a}$. Opinião e está em sua 5‥ edição; os encontros organizados pela Marcha Internacional das Mulheres, cuja 9a.. edição foi em São Paulo, em 2013; e os encontros do The Magdalena Project no Brasil: Vértice Brasil organizado com bravura por Marisa Naspolini, em Florianópolis (SC), Solos Férteis - Festival Internacional de Mulheres no Teatro, em Brasília (DF), Multicidade - Festival Internacional de Mulheres nas Artes Cênicas, no Rio de Janeiro (RJ), Magdalena 3a Geração, em Jundiaí (SP). Estes são alguns encontros, acadêmicos ou não, que propagam as articulações e compartilhamento de saberes feministas e incentivam a formação de redes de mulheres artistas pesquisadoras, em oposição à dinâmica usual de omissão e/ou subinclusão de temáticas de gênero em encontros oficiais de pesquisas em Artes Cênicas.

\section{Os feminismos estão na moda}

Outro fator relacionado ao crescente interesse pelos feminismos na pesquisa acadêmica em Artes Cênicas é o contexto de avanços e propagações dos movimentos feministas no país. Nestes últimos anos - transcorridos sob muita instabilidade e fluxo de acontecimentos implacáveis no cenário político do Brasil, em que a primeira mulher eleita Presidente da República foi retirada do seu cargo ${ }^{17}$ - há uma vigorosa mobilização de diferentes frentes e entidades feministas com inúmeras pautas que contemplam as multiplicidades identitárias e subjetivas inter-relacionais e alianças variáveis presentes na dinâmica dos movimentos sociais. Uma delas é a entrada de jovens mulheres aderindo às causas feministas. ${ }^{18} \mathrm{~A}$ internet e as redes sociais virtuais ampliaram a visibilidade das demandas feministas e ajudaram a difundir e articular informações, fóruns, denúncias, encontros e mobilizações em atos e marchas. Diante das evidências, Margareth Rago - embora apresente ressalvas em relação ao modo como as mídias tratam os temas dos feminismos e criam estereótipos para as feministas - chega a declarar que o "feminismo tornou-se pop, está na moda". ${ }^{19}$

O ciberfeminismo, por exemplo, tem sido uma ferramenta semeadora de ativismos virtuais feministas que, ao final, somam-se aos movimentos sociais e ocupam as ruas das cidades brasileiras em atos. Emerge a partir da progressão crescente de sites com temáticas das mulheres com descentralização na produção e circulação de conteúdos, como o blog coletivo Blogueiras Feministas ${ }^{20}$; Escreva Lola, Escreva, ${ }^{21}$ criado pela professora da Universidade Federal do Ceará Lola Aronovich;

\footnotetext{
${ }^{16}$ A edição do encontro ELLA de 2015 foi na cidade de Cochabamba, Bolívia; e o de 2017 foi em Cali, Colômbia. Mais informações em: < https://medium.com/ ella2017pt>. Acesso em: set. 2018.

${ }^{17}$ Refiro-me ao processo de impeachment da presidenta Dilma Rousseff, em 31 de agosto de 2016.

${ }^{18}$ Um exemplo de mobilização feminista da juventude foi a concentração e atuação de jovens mulheres estudantes secundaristas nas ocupações das escolas públicas diante da discrepante reestruturação do sistema educacional nacional, em diversas cidades brasileiras, no ano de 2016.

${ }^{19}$ Depoimento de Margareth Rago diante da apropriação das mídias de massa ao tratarem os temas dos feminismos, visto pela pesquisadora como algo "perverso" e que banaliza determinados feminismos, assim como cria estereótipos para as mulheres feministas. Coligido na conferência "Da insubmissão feminista na atualidade", para o programa Café Filosófico, veiculado na TV Cultura, 6 de novembro de 2016. Disponível em: <https://www.youtube.com/watch?v=gh67t3a9Mjs>. Acesso em: set. 2018.

${ }^{20}$ Disponível em: <https://blogueirasfeministas.com>. Acesso em: set. 2018.

${ }^{21}$ Disponível em: <www.escrevalolaescreva.blogspot.com.br>. Acesso em: set. 2018.
} 
e Think Olga ${ }^{22}$ projeto feminista idealizado em 2013 pela jornalista Juliana de Faria. E campanhas de denúncia à violência contra a mulher, como "Deixa Ela em Paz", coletivo feminista que promove ações de ocupação do espaço público por mulheres, criando formas de combater a violência e a discriminação de gênero; e "Chega de Fiu

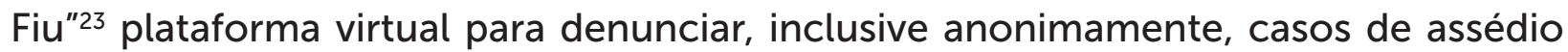
sexual em locais públicos. Muitos dos ativismos virtuais são divulgados em redes sociais e reverberam em atos públicos, como a Marcha das Vadias (Slut Walk), criada em 2011, em Toronto (Canadá) e rapidamente difundida no Brasil por organizações autônomas de jovens feministas contra a cultura do estupro e em defesa da liberdade do corpo das mulheres. ${ }^{24}$ Outro caso semelhante foi o ato "Por Todas Elas" que teve manifestações em mais de cinquenta cidades brasileiras simultaneamente, a partir de convocatórias via Facebook, após o caso de estupro coletivo de jovem carioca de 16 anos por 33 homens, no Rio de Janeiro, no início de 2016. ${ }^{25}$ E tantas outras conexões e aderências em redes que também colaboram para a visibilidade, disseminação dos feminismos no país e empoderamento das mulheres, mediante denúncia de atrocidades envolvendo mulheres, como recentemente o "Marielle, presente!"26 e o ato "Mulheres contra Bolsonaro" ou "\#EleNão"27, criado por mulheres via Facebook e levou milhares de pessoas às ruas de várias cidades brasileiras.

A presença desses levantes reivindicatórios articulados pelos movimentos sociais ou pelo ativismo virtual feminista, acaloram as pesquisas acadêmicas que tomam o sujeito mulher como objeto de investigação e vice-versa. Nessa relação, a produção de conhecimento e saberes feministas, e suas articulações em diferentes áreas de conhecimento, podem e devem estar colados às as pautas dos movimentos sociais em uma dinâmica retroalimentação e reciprocidade mútuas. A construção de saberes dá-se, nesse sentido, pela experiência dos modos de existir e suas subjetividades, nas lutas cotidianas contra os regimes regulatórios, quanto na elaboração de uma articulação crítica e produção de conhecimento acadêmica. No Brasil de hoje, faz-se imprescindível uma convocação - urgente! - para que as diacronias feministas estejam notoriamente em presença também nas "ruas", ampliando o coro de mulheres em

\footnotetext{
22 Disponível em: <https://thinkolga.com>. Acesso em: set. 2018.

${ }^{23}$ Disponível em: <www.chegadefiufiu.com.br>. Acesso em: set. 2018.

${ }^{24}$ A Marcha das Vadias surgiu em reação aos frequentes casos de estupro de jovens estudantes da Universidade de Toronto, "culpadas" por provocá-los por se vestirem como sluts, ou seja, como vagabundas, putas, vadias. No Brasil, o movimento tem sido promovido por ações autônomas de jovens feminista, divulgado via internet e apoiado por diversas entidades feministas, em cidades como São Paulo, Rio de Janeiro, Vitória, Recife, Fortaleza, Salvador, Goiânia, Belo Horizonte, Brasília, Curitiba, Florianópolis, Porto Alegre etc., e já faz parte do calendário de ativismos feministas.

${ }^{25} \mathrm{O}$ caso, que ocorreu em maio de 2016, gerou reações nas redes sociais. Organizações feministas convocaram atos públicos e marcha de mulheres ocupando simultaneamente as ruas de mais de cinquenta cidades brasileiras, em repúdio à cultura do estupro. Em São Paulo, a primeira edição que aconteceu em $1^{\circ}$ de junho reuniu aproximadamente 30 mil mulheres. Informações disponíveis em: <http://brasil.elpais.com/brasil/2016/05/27/politica/1464360226_852010.html>. Acesso em: set. 2018.

${ }^{26}$ No dia seguinte à execução da vereadora Marielle Franco (PSOL), em 15 de março de 2018, foram organizados atos "Marielle, presente!", em diversas cidades do Brasil e também no exterior, como em New York, Montevidéu, Lisboa, Buenos Aires. Essas manifestações foram organizadas, principalmente, por mulheres ativistas de diferentes frentes e entidades. "A execução de Marielle Franco foi um crime misógino e racista. Para muitos ainda é insuportável para ver uma mulher negra, da periferia e que ama mulheres fazer tudo que ela fazia e defendia". Disponível em: <https://blogueirasfeministas.com/2018/03/15/marielle-franco-presente-por-ela-e-por-todas-nos>. Acesso em: set. 2018.

${ }^{27}$ Grupo virtual criado no Facebook, em setembro de 2018, às vésperas do processo eleitoral, convoca todas as mulheres, cis e trans a se reunir contra o machismo, misoginia e outros tipos de preconceitos representados pelo candidato Jair Bolsonaro (PSL) e seus eleitores. As ativistas virtuais lançaram campanhas e promoveram atos em diversas cidades brasileiras e no exterior, no dia 29 de setembro de 2018 . Milhares de pessoas foram às ruas na recusa de políticos que defendem os discursos de ódio, sexistas, homofóbicos, racistas. Disponível em: <https://istoe.com.br/cidades-brasileiras-recebem-atos-contra-bolsonaro>. Acesso em: set. 2018.
} 
intervenção no tecido social e político.

\section{Por mais epistemologias feministas e decoloniais}

Outro motivo da incidência destas pesquisas empreendidas por mulheres-pesquisadoras encontra-se no interesse pela articulação crítica dos saberes teóricos e práticos que justifiquem a sua arte. São produções científicas e artísticas que necessitam de outras abordagens insurgentes nos níveis epistêmico, político e cultural. É na intersecção de trânsitos possíveis entre as atuais teorias feministas, a criação artística e o ativismo social, colocadas frente a frente, que emerge a desarticulação do androcentrismo institucional, criando espaços arejados para a emergência de outras epistemológicas feministas e decoloniais feita de fissuras e aporias. É uma atitude de rebeldia e resistência diacrônica que convoca as identidades marginalizadas para tomar o centro das discussões sob os vieses político, ético e poético.

As epistemologias feministas (Butler, 2008; Haraway, 2009; Rago, 1998; Scott, 1995; entre outras) e decoloniais (Alcoff, 2016; Ribeiro, 2017; Lugones, 2014; Walsh, 2012, para citar apenas as teóricas) têm sido usadas nas pesquisas acadêmicas correlacionadas com a arte num campo expandido para a articulação de contra narrativas estéticas em relação aos discursos de poder arraigados pelos regimes regulatórios e dominantes. Margareth Rago (1998), por exemplo, enfatiza que as perspectivas que vêm se abrindo com os núcleos de consolidação de epistemologias feministas no meio acadêmico giram em torno da conquista e legitimação de um espaço de reflexão e ação, bem como na disseminação da produção de conhecimentos e incorporação de uma perspectiva feminista de gênero na produção e transmissão dos saberes científicos. Rago atenta para as contribuições e perspectivas da práxis para o avanço dos estudos feministas e suas intervenções na sociedade, em particular, na transformação do cotidiano da própria vida acadêmica:

\footnotetext{
Na consideração da existência de uma/várias epistemologia/s feminista/s, valeria então destacarmos, de início, dois pontos: o primeiro aponta para a participação do feminismo na ampla crítica cultural, teórica, epistemológica em curso [...]. Esta crítica revela o caráter particular de categorias dominantes, que se apresentam como universais; propõe a crítica da racionalidade burguesa, ocidental, marxista incluso, que não se pensa em sua dimensão sexualizada, enquanto criação masculina, logo excludente. Portanto, denuncia uma racionalidade que opera num campo ensimesmado, isto é, a partir da lógica da identidade e que não dá conta de pensar a diferença. [...] O segundo, embutido no primeiro, traz as propostas desta nova forma de conceber a produção do conhecimento, do projeto feminista de ciência alternativa, que se quer potencialmente emancipador. (Rago, 1998, p.4)
}

O projeto feminista de ciência alternativa promove, assim, linhas de fuga para promover a desarticulação da hegemonia epistemológica. Percebe-se também uma demanda em visibilizar outras experiências do conhecimento como proposta de decolonizar saberes e refutar a neutralidade epistemológica, ou seja, uma demanda por decolonizar a academia (Alcoff, 1997). Contra a perpetuação de epistemologias que colonizam as reivindicações de conhecimento e geram manutenção da hege- 
monia do pensamento crítico e considerando identidade e localização dos sujeitos/ sujeitas de conhecimento como ponto de partida, a filósofa panamenha Linda Martín Alcoff chama a atenção, em seu texto Uma epistemologia para a próxima revolução (2016), para uma epistemologia da libertação. Libertação esta que abriga demandas por uma agenda produzida mediante a criação e a institucionalização de programas de pesquisa, em estudos feministas, de gênero e diversidades, dos estudos pós-coloniais e decoloniais, cuja omissão e distorção requerem uma reforma disciplinar, incluindo novas metodologias de investigação (Alcoff, 2016, p.142).

Apoiada no feminismo interseccional, a filósofa Djamila Ribeiro, em seu livro 0 que é lugar de fala (2017), lembra que Alcoff sobressai o fato de que para descolonizarmos o conhecimento, precisamos nos ater à identidade social, "não somente para evidenciar como o projeto de colonização tem criado essas identidades, mas para mostrar como certas identidades têm sido historicamente silenciadas e desautorizadas no sentido epistêmico, ao passo que outras são fortalecidas" (Ribeiro, 2017, p. 29). A fim de desenvolver teorias e arte que reflitam diferentes perspectivas sociais, há uma urgência em deslocar o pensamento hegemônico para as subjetividades, enaltecer o lugar de fala e ressignificar as identidades a partir de seus predicados que antes eram tidos como pejorativos de falta, inabilidade e marcadores sociais. Raça, gênero, classe podem e devem:

[...] construir novos lugares de fala com o objetivo de possibilitar voz e visibilidade a sujeitos que foram considerados implícitos dentro da normatização hegemônica. [...] O falar não se restringe ao ato de emitir palavras, mas de poder existir. Pensamos o lugar de fala como refutar a historiografia tradicional e a hierarquização de saberes consequente da hierarquia social. (Ribeiro, 2017, p. $43 ; 53)$

Grupos invisibilizados e inferiorizados de mulheres (trans, lésbicas, indígenas, negras, latinas, mestiças, imigrantes, periféricas etc.) aparecem no pensamento decolonial e interseccional como categorias fundamentais no enfrentamento às colonialidades e são colocadas no centro de suas discussões identitárias e emancipatórias também nas artes. A epistemologia decolonial articula outros modos de pensar, de ser e agir. Há um compromisso com o global, com a justiça, com o lugar da fala de todos. É uma aposta, um projeto de vida de "re-existir, sentir-pensar y con-vivir en las grietas del orden dominante y de la matriz moderno/colonial" (Walsh, 2014).

E como aposta de sentir-pensar, as epistemologias da "libertação" têm sido manejadas recorrentemente nas pesquisas em Artes Cênicas como interlocução com as práticas contraventoras feministas. O alcance dessas articulações epistemológicas nas políticas do corpo e das artes regem espaços de experimentação identitária em que as diferenças são aceitas, estimuladas, e as relações de poder denunciadas. Nas artes da cena são criadas estratégias metodológicas, nas quais teoria e a prática artística estão estreitamente tecidas em abordagens multidisciplinares que analisam, muitas vezes, o próprio fazer artístico à luz das teorias críticas feministas. Ou ainda pesquisas que desenvolvem análises de espetáculos teatrais e intervenções performáticas de cunho etnográfico que manifestam posturas críticas, políticas e poéticas enquanto reivindicação social, com tendências a promover a interlocução entre arte, 
cidadania e modos de existir das mulheres.

\section{Convocatória para re-existir e resistir}

Embora, todavia não haja disponível um levantamento pormenorizado que disponibiliza estatísticas quantitativas ou qualitativas sobre a incidências das pesquisas feministas nos Cursos de Artes Cênicas no Brasil, não há mais como negar a sua existência e valorização em diversas instituições nacionais. ${ }^{28}$ Equivale a dizer que houve uma contemporização, ou melhor, uma ressignificação dos discursos feministas nas pesquisas científicas e práticas artísticas. O que antes soava pejorativo - muitas vezes por estarem atreladas ao engajamento político e ao suposto esgotamento do discurso feminista das décadas anteriores (Romano, 2009, p. 586) - enunciar-se artista feminista nos dias de hoje pode ser definido como uma tendência. Reflexo direto dos "novos discursos" de gênero e engajamento para promover uma arte ativista com orientação feminista em contraponto às clássicas problemáticas dos feminismos que se atualizam - pensando no recorte geográfico da América Latina.

E essa constatação se dá, sobretudo, por vivenciar o crescente número de pesquisas feministas no bojo acadêmico que vão ao contra fluxo da neutralidade histórica da ocupação das mulheres nos mais diferentes campos da criação cênica (em direção, dramaturgia, atuação, iluminação, cenografia, produção, manutenção de grupos, pedagogias, criação de metodologias e treinamentos técnicos próprios para o corpo das mulheres). Também na sucessiva criação de encontros e seminários centrados na temática das mulheres e suas visibilidades sociais. E nas ruas que são tomadas por milhares de mulheres, juntas, vindas da academia e/ou do movimento social (não importa a sua origem e formação), em luta e fazendo coro de reivindicações de seus direitos.

Essa crescente incidência constitui um indicativo da necessidade de evidenciar a posição das mulheres artistas pesquisadoras na academia e nos sistemas simbólicos, como sujeitas de enunciação, investidas na construção de conhecimentos científicos, estéticas e poéticas cênicas. Também se faz impreterível atender os estudos feministas e de gêneros nos cursos superiores de formação da/o artista e convocar ações pedagógicas que os contemplem, pois é no reconhecimento das forças sistêmicas e institucionais de opressão que grupos invisibilizados e silenciados adotam atitudes desestabilizadoras e arbitrárias e atualizam suas temáticas.

Esta reflexão encerra-se com a convocatória para que juntas criemos ações na academia para erradicarmos o estatuto marginal e toda forma de negligências que, todavia, rondam as produções cientificas das mulheres pesquisadoras. Devemos enaltecer e incentivar nossa atuação nos programas de graduação e pós-graduação, nos compromissos de decolonização epistêmica, criar mais grupos de estudos para romper com as omissões nos encontros oficiais de pesquisa em Artes Cênicas, incen-

\footnotetext{
${ }^{28}$ Vale evidenciar que a tese de doutorado de Stela Fischer (Mulheres, performance e ativismo: a ressignificação dos discursos feministas na cena latino-americana, com orientação da Profa. Dra. Beth Lopes) foi premiada com o Prêmio Capes de Tese 2018 de melhor tese em Artes da Escola de Comunicação e Artes da Universidade de São Paulo. Esse prêmio é um demonstrativo de interesse acadêmico na atualidade por teses que impulsionam abordagens de outras epistemologias (feministas e decoloniais) e estabelecem uma reação crítica diante da predominância dos saberes hegemônicos e/ou androcêntricos institucionai.
} 
tivar produções bibliográficas que desconstruam o perverso jogo de saber e poder das relações institucionais que geram omissões e desigualdades. Não para deslegitimar a produção intelectual dos homens, (que sempre estiveram no lugar de privilégio e pouco - ou nada - fizeram para mudar esse cenário e incluir os invisibilizados), mas para criar fissuras na hegemonia epistemológica, por meio das quais possam repercutir as vozes das mulheres pensadoras nas artes. Nós, pesquisadoras, teóricas e artistas devemos ser lidas, estudadas e insistentemente citadas porque produzimos, sim, um conhecimento científico e artístico de resistência. Aqui fica a convocatória por um ato contínuo de engajamento contra o silenciamento histórico das mulheres na produção de conhecimento acadêmico, a fim de valorar nossas colaborações. Uma convocatória também para que nossas pesquisas possam reverberar e ocupar as ruas, coladas aos movimentos sociais nesse momento de antagonismos políticos que efetuam exclusão da cidadania e incentivam a precarização da vida e violência. Nesse momento de reedições de disciplinamento dos modos de existir, resistiremos.

\section{Referências}

ALCOFF, Linda M. Uma epistemologia para a próxima revolução. Sociedade e Estado. Brasília, n. 1, v. 31, jan/abr, 2016. Disponível em: <http://periodicos.unb.br/index.php/ estado/article/view/21425/15326>. Acesso em: set. 2018.

BATISTA, V.; RAUEN, Margarida G. A desarticulação do androcentrismo e da discriminação interseccional por meio do ensino da arte contemporânea. Revista PÓS: do Programa de Pós-Graduação em Artes da EBA/UFMG. V. 7, n. 14, nove. 2017. Disponível em: <https://www.eba.ufmg.br/revistapos/index.php/pos/article/view/580>. Acesso em: set. 2018.

Ensino e inclusão curricular de dramaturgas e mulheres artistas. In: Teatro e ensino (1) - estratégias de leitura do texto dramático. São Carlos: Pedro \& João Editores, 2017, p. 91-106.

BUTLER, Judith. Quadros de guerra: quando a vida é passível de luto? Rio de Janeiro: Civilização brasileira, 2015.

Problemas de gênero: feminismos e subversão da identidade. Rio de Janeiro: Civilização Brasileira, 2008.

HARAWAY, Donna."Manifesto ciborgue - ciência, tecnologia e feminismo-socialista no final do século XX", in: In: KUNZRU, H. e TADEU T. (Org.). Antropologia do ciborgue: as vertentes do pós-humano. Belo Horizonte: Autêntica Editora, 2009.

LYRA, Luciana. O Motim, cartografando rastros e vestígios de pesquisas tramadas por mulheres nas Artes da Cena. Revista Arte da Cena, Goiânia, v. 3, n. 1, p. 3-7. Jan-jul/2017. Disponível em: <https://www.revistas.ufg.br/artce/article/view/48153>. Acesso em: set. 2018. 
LAURETIS, Teresa de. Diferencias: etapas de un camino a través del feminismo. Madrid: horas y HORAS, 2000.

LUGONES, María. Rumo a um feminismo descolonial. Revista Estudos Feministas, set-dez, 2014. Disponível em: <https://periodicos.ufsc.br/index.php/ref/article/ view/36755>. Acesso em: set. 2018.

MIRANDA, Maria Brígida de. Entrevista concedida a Stela Fischer, setembro de 2018.

RAGO, Margareth. Epistemologia feminista, gênero e história. In: PEDRO, Joana Maria e GROSSI, Miriam Pilar (Org.). Masculino, feminino, plural. Florianópolis: Editora Mulheres, 1998, p. 25-37. Disponível em: <http://projcnpq.mpbnet.com.br/textos/ epistemologia_feminista.pdf>. Acesso em: set. 2018.

RAUEN, Margarida (Margie) G. A busca de presença e as restrições da teorização acerca de mulheres e gênero no Sul. Seminário Internacional Fazendo Gênero 11 \& 13 th Women's Worlds Congress (Anais Eletrônicos), Florianópolis, 2017. Disponível em: <http://www.wwc2017.eventos.dype.com.br/resources/anais/1503111901_ ARQUIVO_Rauen2017-FazendoGen11finalb.pdf. Acesso em set. 2018>. Acesso em: set. 2018.

RIBEIRO, Djamila. O que é lugar de fala? Belo Horizonte: Letramento, 2017.

ROMANO, Lúcia R. V. De quem é esse corpo? A performatividade do feminino no teatro contemporâneo. Tese (Doutorado). São Paulo: Departamento de Artes Cênicas, Escola de Comunicação e Artes, Universidade de São Paulo, 2009.

SCOTT, Joan Wallach. Gênero: uma categoria útil de análise histórica. Educação \& Realidade. Porto Alegre, vol. 20, n 2, jul./dez. 1995.

WALSH, Catherine. Notas pedagógicas desde las grietas decoloniales. E-misférica, volume 11, n.1. 2014. Disponível em: <http://hemisphericinstitute.org/hemi/es/e-misferica-111-gesto-decolonial/walsh>. Acesso em: set. 2018.

Recebido em: 30/09/2018

Aprovado em: 27/10/2018 